\title{
THE HOLMES-ADIE SYNDROME IN A BOY WITH ACUTE JUVENILE RHEUMATISM AND BILATERAL SYNDACTYLY
}

\author{
BY \\ J. M. LITTLEWOOD and G. M. LEWIS \\ From the Department of Paediatrics and Child Health, The University of Leeds
}

(RECEIVED FOR PUBLICATION SEPTEMBER 28, 1962)

Brain (1955) describes the Holmes-Adie syndrome as 'of unknown aetiology and pathology characterized in its fully developed form by abnormalities in the reaction of one or both pupils to light and accommodation and absence of tendon reflexes'.

The usual pupillary abnormality is a unilateral large regular pupil which shows the tonic pupillary reaction in response to light and accommodation.

Many writers refer to variations in the physical findings and Adie himself recognized incomplete forms of the syndrome (Adie, 1932). The pupillary changes are bilateral in approximately one-third of cases. The affected pupil may be small or there may be irregularity of the pupils. Atrophy of the iris has been described. These and other variants have been reviewed by Russell (1957).

Although well recognized in both sexes, the condition commonly presents suddenly in healthy young women. The classical syndrome in childhood is very rare (Ford, 1960). In so far as we have been able to ascertain from the published material, the youngest observed case is the 18-yearold girl described by Foster Moore (1924); the mother had noted the abnormal pupil from birth and an ophthalmologist had observed the condition at 5 years.

The present case is of interest because of the concurrent onset of pupillary abnormalities and acute juvenile rheumatism, in a child with a dominant congenital anomaly (syndactyly). Changes of unknown duration in the tendon jerks were present.

\section{Case Report}

A 7-year-old boy was admitted to hospital on February 2, 1962. He had been well until 10 days previously when he developed pain and swelling of the left hallux and ankle. Radiological examination at this time revealed no abnormality, and the swelling settled without treatment in the course of a few days. Three days before admission, pain, swelling and redness developed in the left ankle, and the boy became feverish, appearing generally unwell.

There was no history of tonsillitis. skin rashes, trauma or chorea before admission. The mother had noted. four days before he was admitted, that the pupil of his right eye was larger than that of his left. This had not been noted previously.

Perinatal history was uneventful. Delivery was at term, birth weight being $5 \mathrm{lb}$. $12 \mathrm{oz}$. (2.59 kg.). Syndactyly of both fourth and fifth digits was noted at birth. Developmental progress and intelligence are normal. Both parents are well. The father has syndactyly of both fourth and fifth digits and had rheumatic fever at 7 years; father and son have similar facial features. Two older siblings are normal.

Examination on Admission. Weight $45 \frac{1}{4}$ lb. (20.52 kg.). height 47 in. $\left(119 \mathrm{~cm}\right.$.), temperature $98 \cdot 2^{\prime}$ F. $\left(36 \cdot 8^{\circ} \mathrm{C}.\right)$. respiration $30 / \mathrm{min}$, pulse $120 / \mathrm{min}$. The boy was not severely ill, but complained of pain in his left hip. preferring to lie on his right side with the left hip slightly flexed. His facial appearance was unusual, the external nares being small, the nasal bridge wide with associated epicanthic folds, and the right pupil larger than the left. The tongue was smooth. The pulse rate was $120 / \mathrm{min}$. at rest. There was no cardiac enlargement: a short localized systolic murmur was present immediately internal to the apex. All joints were normal with the exception of the left hip in which there was pronounced pain and limitation of movement with associated flexion deformity. There was bilateral syndactyly of both fourth and fifth digits (Fig. 1). There was no lymph node enlargement or splenomegaly, and the tonsils were not inflamed.

Central nervous system examination revealed absent knee and ankle jerks, and pupillary abnormalities (Fig. 2). The left pupil was of normal size and shape in marked contrast to the right pupil which was large and not completely circular. The left eye reacted normally to light and accommodation, whereas the right eye did not respond to light immediately and contracted slowly after four minutes with marked hippus until smaller than the other pupil. On removing the light stimulus there was a slow return of the right pupil to its previous abnormal size.

Although constriction of the right pupil was not evoked by requiring the boy to look at a near object for a long period (approximately five minutes), it was noted on one isolated occasion that constriction was present after the patient had been reading for some time. 
Subsequent Progress and Treatment. On the day after admission the boy became pyrexial, and developed erythema marginatum over the chest. The sleeping pulse rate was 110 per minute and the resting pulse rate 130 per minute. During the next six days he remained pyrexial and developed pain, swelling, redness, and limitation of movement of both wrists, the right ring finger and the left ankle. Pain developed in the right hip also. The joint pains were flitting in character, each joint being involved for about 24 to 48 hours. Pyrexia and joint symptoms settled within 48 hours after starting salicylate therapy on the fifth day. Penicillin was given for one week intramuscularly from the day of admission and thereafter orally.

After the first week there were no further joint symptoms, and the temperature remained normal. The sleeping pulse rate settled to 80 beats per minute and the boy started to gain weight. E.S.R. levels returned to normal by the end of the second week. Salicylates were withdrawn gradually in the fifth week. Complete bedrest was maintained for the first month with gradual return to normal activity by three months.

The soft systolic murmur noted on admission remained unchanged throughout the boy's stay in hospital. Six months after admission the right pupil remained abnormal and tendon reflexes were still absent.

\section{Special Investigations}

Urine contained trace of albumin (30 mg. $100 \mathrm{ml}$.): normal microscopy; Hb $80 \%$ (11.9 g.), W.B.C. 17,000, neutrophils $74 \%$; lymphocytes $17 \%$; monocytes $9 \%$; E.S.R. (Westergren) $25 \mathrm{~mm}$./hour; red cell morphology normal; blood for L.E. cells, negative; Mantoux 1/1,000, negative; throat swab contained scanty growth of Candida albicans; haemolytic streptococci were not isolated. Blood culture was negative.

Antistreptolysin titre 333 Todd units $/ \mathrm{ml}$. C-reactive protein positive; Wassermann reaction (blood), negative; gonococcal complement-fixation test, negative; serology for Brucella abortus and salmonella, negative: serum antibody tests for influenza A.B., psittacosis, $Q$ fever, adenovirus, mumps, poliomyelitis, Paul Bunnell, Streptococcus M.G. - all negative.

Toxoplasma serology dye test 1/8; complement fixation $1 / 8$ (negative); plasma proteins: serum albumin $3.9 \mathrm{~g}$., globulin $2.8 \mathrm{~g}$., total $6.7 \mathrm{~g}$.

Plasma protein electrophoresis, normal: Rose-Waaler, negative.

Serum vitamin $\mathrm{B}_{12}$ level, $371 \mu \mu \mathrm{g} . \mathrm{ml}$.

\section{Discussion}

It can be accepted that this child had an attack of acute juvenile rheumatism, and there is little doubt that he presented also the signs of a HolmesAdie syndrome. The evidence points to the pupillary signs having appeared simultaneously with the onset of the attack of acute rheumatism. It is known that the boy's pupils were normal at a school medical examination at the age of $5 \frac{1}{2}$ years. There

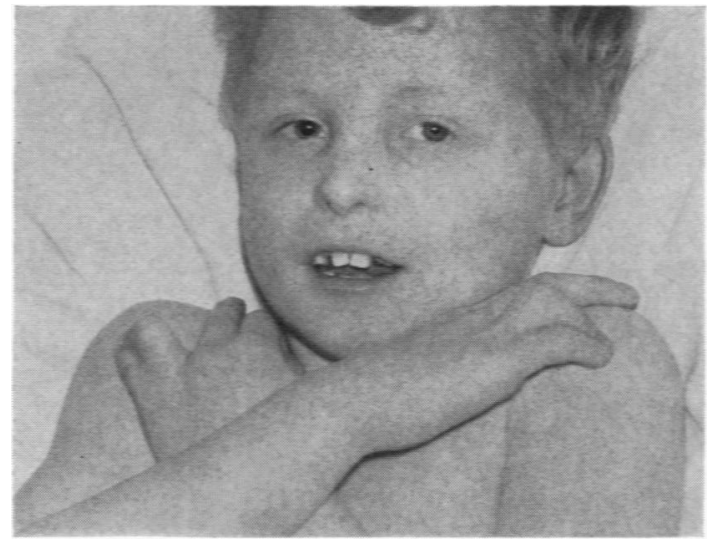

Fig. 1.-Syndactyly.

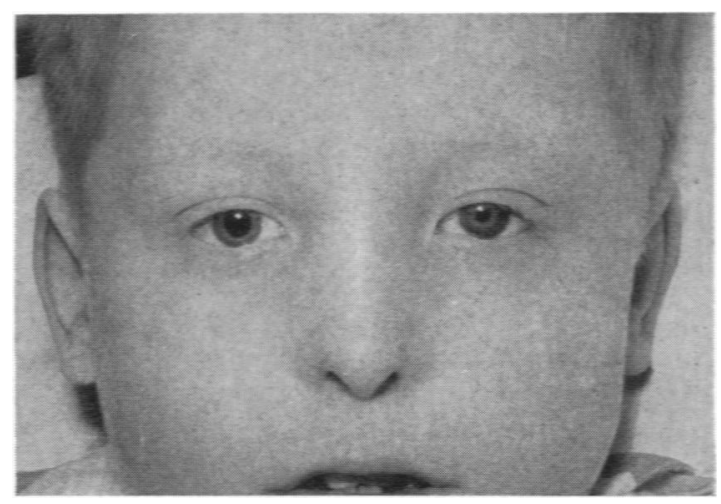

FG. 2.-Large. not completely circular right pupil that contracted to light only very slowly and with pronounced hippus.

is no evidence of any abnormality of the pupils in photographs taken at the age of 18 months and $6 \frac{1}{2}$ years. As already stated, the mother first noted inequality of the pupils four days before the boy was admitted to hospital. The duration of areflexia in the lower limbs is not known.

According to Russell (1957) the Holmes-Adie syndrome has been found in association with a wide variety of conditions such as encephalitis, pernicious anaemia, disseminated sclerosis, diabetes, Raynaud's disease, diphtheria, narcolepsy, syphilis, head trauma and orbital abnormalities. So far as we can ascertain there has not been previous mention of an association between acute juvenile rheumatism and the Holmes-Adie syndrome. Moreover, the apparent simultaneous onset of articular and pupillary signs suggests that there may have been a common aetiological factor. 


\section{Summary}

A case is described in which the signs of the Holmes-Adie syndrome appeared to develop simultaneously with those of acute juvenile rheumatism in a boy who was 7 years of age and in whom there was syndactyly.

We wish to thank Professor W. S. Craig for much helpful advice.

\section{REFERENCES}

Adie. W. J. (1932). Tonic pupils and absent tendon refiexes Brain, $55,98$.

Brain, W R. (1955). Diseases of the Nervous System, 5th ed. Oxford University Press, London.

Ford. F. R. (1960). Diseases of the Nervous System in Infancy and Adolescence, 4th ed. Blackwell, Oxford.

Moore. F. (1924). In Discussion on the physiology and pathology of the pupil reactions. Trans. ophthal. Soc. U.K, 4, 38.

Russel!, G. F. M. (1957). The pupil and accommodation. M.D. Thesis. University of Fdinburgh. 